\title{
Simulation research of the temperature distribution during face milling
}

\author{
Malgorzata Blasiak $^{1, *}$, Lukasz Nowakowski ${ }^{2}$ \\ ${ }^{1}$ Department of Mechanics, Kielce University of Technology; Aleja Tysiąclecia Państwa Polskiego 7; 25-314 Kielce, Poland \\ ${ }^{2}$ Department of Mechanical Technology and Metrology, Kielce University of Technology; Aleja Tysiąclecia Państwa Polskiego 7; \\ 25-314 Kielce; Poland
}

\begin{abstract}
The paper presents the results of numerical calculations showing the temperature distribution of the workpiece (copper) during the face milling process. The ANSYS program was used for simulation studies. The calculations were carried out for two different cutting speeds, examining their influence on the temperature of the workpiece. The calculations constitute the basis for further research in order to determine the influence of variable temperature fields on the thermal expansion of the workpiece and to estimate the dimensional accuracy of the parts to be made during milling.
\end{abstract}

\section{Introduction}

During metalworking, the mechanical energy is converted into heat, causing an increase in temperature during machining. It can be said that the heat flux, i.e. the amount of heat emitted in a unit of time, corresponds to the cutting power. In the machining process we are dealing with a source of heat coming from the work of plastic deformation and chip formation, i.e. separation of the material and from friction on the application surface and from the rake. The heat generated during the machining process is dissipated by the chip, taken over by the material and the tool as well as by the coolant. Part of the heat is also carried into the ambient atmosphereFor ISO N materials - i.e. non-ferrous metals such as aluminium, brass, copper, etc., the percentage distribution of heat flows can be about $70 \%$ for the workpiece, $20 \%$ for the chip and $2 \%$ for the cutting edge [1-3].

There are many ways to measure temperature in the machining process based on conduction, heat radiation and metallographic measurements using knowledge of the melting temperatures of thin metal coatings applied to the blade. However, there is no single optimal method established. Depending on the research carried out, it is expected that the average and maximum temperature at the contact between the chip and the blade can be measured, as well as the temperature distribution over the length of contact or the entire heat flow area [4,5].

Fast and accurate temperature measurement is of particular importance for the use of this information to monitor the condition of the cutting edge. Elevated workpiece temperature in the machining process primarily affects tool wear, but can also lead to a reduction in the performance of machine parts, machine tools, pneumatic valves, non-contact face seals $[6,7]$. In addition, an increase in workpiece temperature during cutting can reduce the accuracy of the machining process related to the thermal expansion of the workpiece material and lead to changes in the structure of the surface layer. As a result of uneven heating, the workpiece can also be deformed. Errors in precision parts due to uncontrolled heating of the workpiece during face milling can cause malfunction of the machine. They can cause faster wear of the cooperating surfaces, which in turn can cause vibrations and frictional resistance. There is therefore a need to develop reliable measurement methods that can be used in machine tools. These are contact methods for determining average temperatures in the cutting zone $[8,9]$ and non-contact methods based on the phenomenon of heat radiation for determining the temperature on the surfaces of the workpiece, tool and chip.

\section{Subject of research}

The aim of this work was to present the temperature distribution of the workpiece during the milling process of the frontal copper alloy. Numerical calculations were performed in ANSYS Workbench.

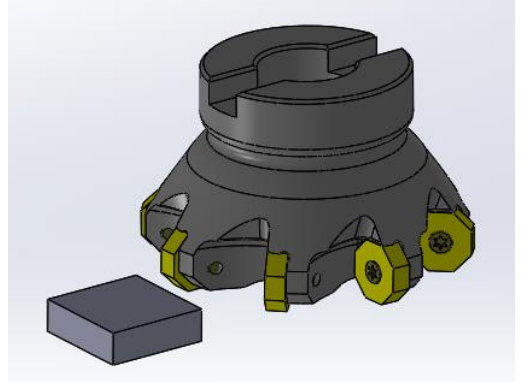

Fig. 1. Scheme of the tested object. 
Fig. 1 shows the workpiece model together with the cutting tool. For calculations, a sample of dimensions (LWH) $30 \times 30 \times 10[\mathrm{~mm}]$ was used. Fig. 2 shows the location of measuring points.

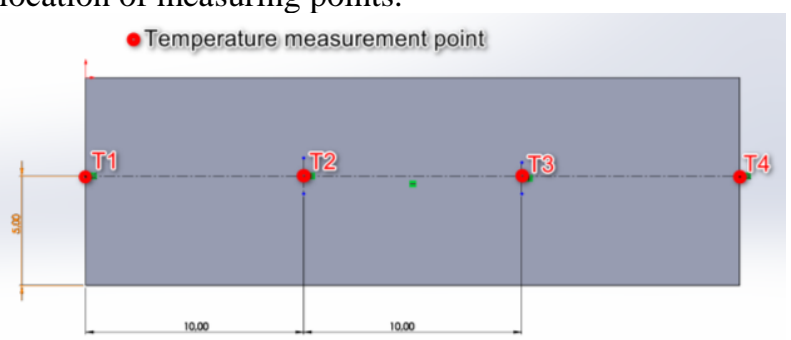

Fig. 2. The location of measuring points.

Table 1. Workpiece dimensions.

\begin{tabular}{|c|c|c|c|c|}
\hline$y$ & $\begin{array}{c}\text { Length L } \\
{[\mathrm{mm}]}\end{array}$ & $\begin{array}{c}\text { Width W } \\
\text { [mm] }\end{array}$ & $\begin{array}{c}\text { Height H } \\
\text { [mm] }\end{array}$ & $\begin{array}{c}\text { Distance h } \\
\text { [mm] }\end{array}$ \\
\hline 1 & \multirow{6}{*}{30} & \multirow{6}{*}{30} & 9.5 & 4.5 \\
\hline 2 & & & 9.0 & 4.0 \\
\hline 3 & & & 8.5 & 3.5 \\
\hline 4 & & & 8.0 & 3.0 \\
\hline 5 & & & 7.5 & 2.5 \\
\hline 6 & & & 7.0 & 2.0 \\
\hline
\end{tabular}

Table 1 shows the dimensions of the workpiece, where $\mathrm{H}$ is the height of the workpiece in the individual milling phases at the depth of machining ap $=0.5[\mathrm{~mm}]$. Distance means the distance of the machined surface from the measuring points (see Fig. 2).

\section{Mathematical model}

In the model under consideration it was assumed that the heat source is the conversion of mechanical work into heat. The heat flux was determined from the following relationships [1]:

$$
Q=\frac{F_{c} v_{c}}{60}[W]
$$

One of the determining parameters influencing the temperature generated during the machining process is the machining velocity. The calculations were made for two different machining velocities $\mathrm{vc}=214.8 \mathrm{i} 315.4$ $[\mathrm{m} / \mathrm{min}]$ for $\mathrm{n}=855 \mathrm{i} 1255[\mathrm{obr} / \mathrm{min}$ ] based on the relation:

$$
v_{c}=\frac{\pi D_{c} n}{1000}\left[\frac{m}{\min }\right]
$$

As the machining velocity increases, more and more of the heat flux generated in the machining zone receives the chip. At very high machining velocities, the produced chip collects virtually the entire heat flux from the machining area.

The value of the force $F_{c}$ in equation (1) was determined using the formula:

$$
F_{c}=A k_{c}[N]
$$

where: $A$ - cross sectional area of the machined layer $\left[\mathrm{mm}^{2}\right], k_{c}$ - specific machining resistance $\left[\mathrm{N} / \mathrm{mm}^{2}\right]$.

Specific machining resistance $k_{c}$ was calculated from the following equations:

$$
k_{c}=\frac{k_{c 1.1}}{h_{m}^{m}}\left[\frac{N}{m m^{2}}\right]
$$

where: $k_{c 1.1}$ - the value of specific resistance for the unit of thickness of the machined layer $\left[\mathrm{N} / \mathrm{mm}^{2}\right], \mathrm{h}_{\mathrm{m}}-$ the average thickness of the machined layer in $[\mathrm{mm}], \mathrm{m}-$ power index.

The average thickness of chips $\left(h_{m}\right)$ where $a_{e} / D_{c} \geq 0.1$ :

$$
h_{m}=\frac{180 \sin \left(\kappa_{r}\right) a_{e} f_{z}}{\pi D_{\text {cap }} \arcsin \left(\frac{a_{e}}{D_{c a p}}\right)}
$$

where: $\kappa_{\mathrm{r}}-$ setting angle ${ }^{\circ}, \mathrm{D}_{\text {cap }}-$ the effective machining diameter to the actual machining depth in [mm] calculated from:

$$
D_{\text {cap }}=D_{c}+\frac{2 a_{p}}{\tan \left(\kappa_{r}\right)}
$$

Input data and calculation results of total heat released per unit of time during face milling for specific conditions of machining have been presented in table 2 .

Table 2. Processing parameters

\begin{tabular}{|c|c|}
\hline Imput Data & Calculated values \\
\hline$D_{c}=80[\mathrm{~mm}]$ & \multirow{2}{*}{$D_{c a p}=81[\mathrm{~mm}]$} \\
\hline$a_{p}=0.5[\mathrm{~mm}]$ & \\
\hline$\kappa_{r}=45\left[{ }^{\circ}\right]$ & $h_{m l}=0.034[\mathrm{~mm}]$ \\
\hline$a_{e}=30[\mathrm{~mm}]$ & $h_{m 2}=0.023[\mathrm{~mm}]$ \\
\hline$f_{z}=0.05[\mathrm{~mm} / \mathrm{tooth}]$ & $k_{c l}=1691.83\left[\mathrm{~N} / \mathrm{mm}^{2}\right]$ \\
\cline { 1 - 1 }$k_{c l .1}=780\left[\mathrm{~N} / \mathrm{mm}^{2}\right]$ & $k_{c 2}=1848.76\left[\mathrm{~N} / \mathrm{mm}^{2}\right]$ \\
\cline { 2 - 3 }$m=0.23$ & $F_{c l}=42.29[\mathrm{~N}]$ \\
& $F_{c 2}=31.42[\mathrm{~N}]$ \\
\hline$v_{c l}=214.8[\mathrm{~m} / \mathrm{min}]$ & $\mathrm{Q}_{1}=151.47[\mathrm{~W}]$ \\
\hline$v_{c 2}=315.4[\mathrm{~m} / \mathrm{min}]$ & $\mathrm{Q}_{2}=165.21[\mathrm{~W}]$ \\
\hline
\end{tabular}

The equation governing the heat transfer process in the investigated element is the diffusion equation, which can be written in the following general form [5]:

$$
\frac{\partial T}{\partial t}=\nabla^{2} T
$$

This equation is implemented in Ansys (Transient Thermal). When solving such a problem, a boundary condition of the third type related to the exchange of heat with the environment through convection has been introduced. This condition can be saved In a form:

$$
\lambda \frac{\partial T}{\partial n}=\alpha^{f}\left(T-T^{f}\right)
$$

where: $\lambda-$ heat transfer coefficient, $T^{f}-$ ambient temperature. The material used in numerical calculations was copper with parameters contained in the Engineering Data Source in Ansys Workbench.

Table 3. Copper properties.

\begin{tabular}{|c|c|c|c|}
\hline Material & $\begin{array}{c}\text { Density } \\
{\left[\mathrm{kg} / \mathrm{m}^{3}\right]}\end{array}$ & $\begin{array}{c}\text { Thermal } \\
\text { Conductivity } \\
{\left[\mathrm{W} / \mathrm{m}^{\circ} \mathrm{C}\right]}\end{array}$ & $\begin{array}{c}\text { Specific } \\
\text { Heat } \\
{\left[\mathrm{J} / \mathrm{kg}{ }^{\circ} \mathrm{C}\right]}\end{array}$ \\
\hline $\begin{array}{c}\text { Copper } \\
\text { Alloy }\end{array}$ & 8300 & 401 & 385 \\
\hline
\end{tabular}


For the calculations it was assumed that the more intensive heat transfer with the environment takes place through the side walls and through the lower surface of the tested element. (Fig. 3).

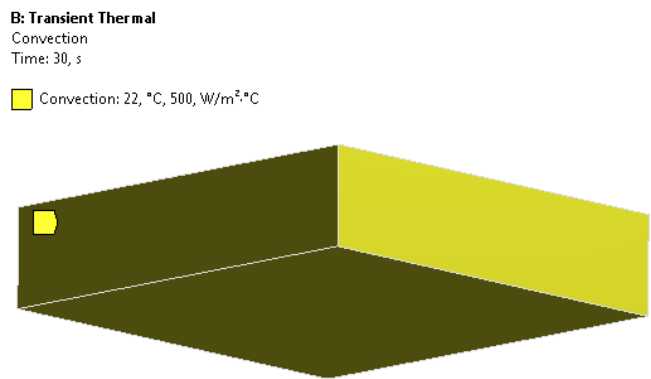

Fig. 3. Convection boundary conditions.

The Ansys (Model) program divides the analyzed element into a spatial computational grid, which is shown in Fig. 4.

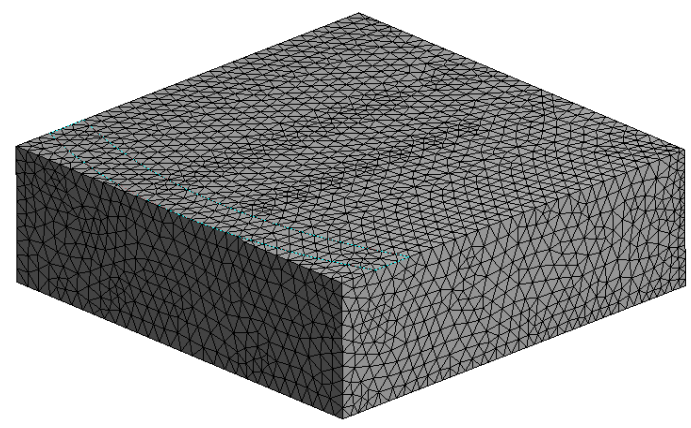

Fig. 4. Finite element mesh.

The grid consists of 7508 notes and 34304 elements. The minimum mesh edge length of the grid is assumed to be $1[\mathrm{~mm}]$.

\section{Results of experimental studies}

Fig. 5 shows graphs of temperature changes during simulation at four control points for machining velocity $\mathrm{v}_{\mathrm{c}}=214.8[\mathrm{~m} / \mathrm{min}]$ and $\mathrm{v}_{\mathrm{c}}=315.4[\mathrm{~m} / \mathrm{min}]$ for the tool distance from measurement points $\mathrm{h}=4.5[\mathrm{~mm}]$.

a)



b)

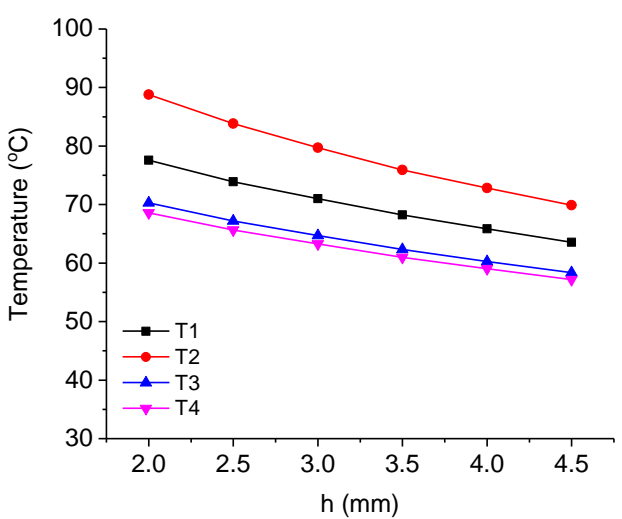

Fig. 5. Maximum temperature distribution for four locations of measuring points and two cutting speeds.

Analyzing the results shown in Fig. 5 it was observed that the maximum temperature of the sample during the simulation was obtained at control point No. 2, equal to $88.7\left[{ }^{\circ} \mathrm{C}\right]$. For control point No. 4 the maximum temperature was $68.5\left[{ }^{\circ} \mathrm{C}\right]$, which was the lowest maximum value determined for all measurement points at $\mathrm{v}_{\mathrm{c}}=315.4[\mathrm{~m} / \mathrm{min}]$.

a)

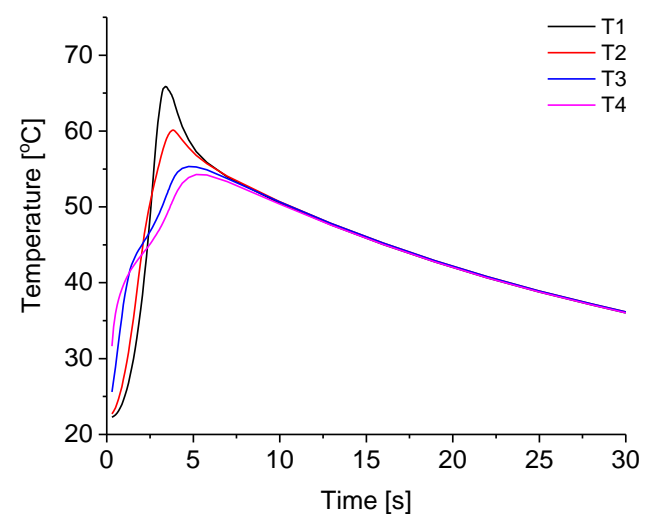

b)

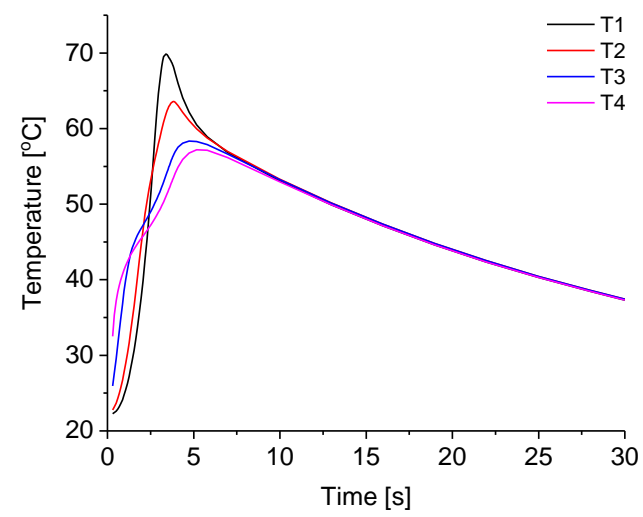

Fig. 6. Temperature distribution for four locations of measuring points a) $\mathrm{v}_{\mathrm{c}}=214.8[\mathrm{~m} / \mathrm{min}]$, b) $\mathrm{v}_{\mathrm{c}}=315.4[\mathrm{~m} / \mathrm{min}]$.

Fig. 6 shows the temperature changes for the two machining velocities at the measuring points at the first pass of the milling head.

Fig. 7 shows graphs of temperature changes for different distances between the tool and control points $\mathrm{T} 1$ with the machining velocity $\mathrm{v}_{\mathrm{c}}=214.8[\mathrm{~m} / \mathrm{min}]$. It can be seen that the temperature increases each time the layer of 
material separating the cutting surface from the machining points decreases.

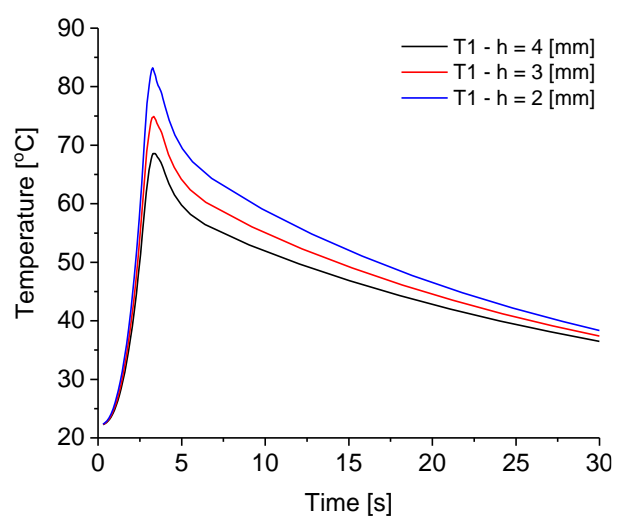

Fig. 7. Temperature changes depending upon the height of the test sample

a)

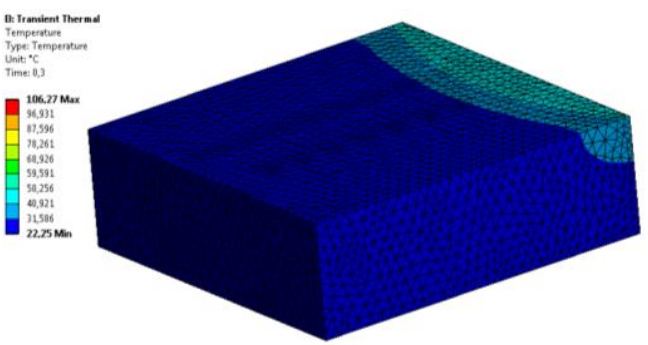

b)

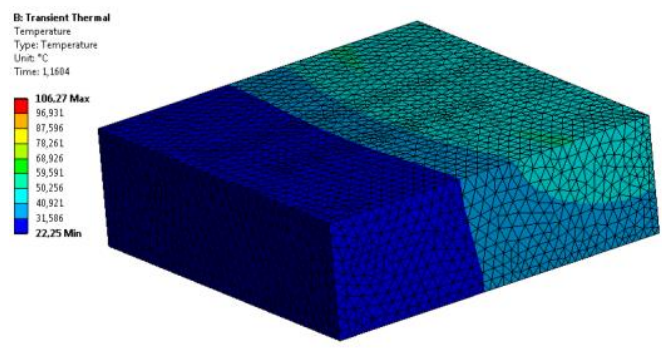

c)

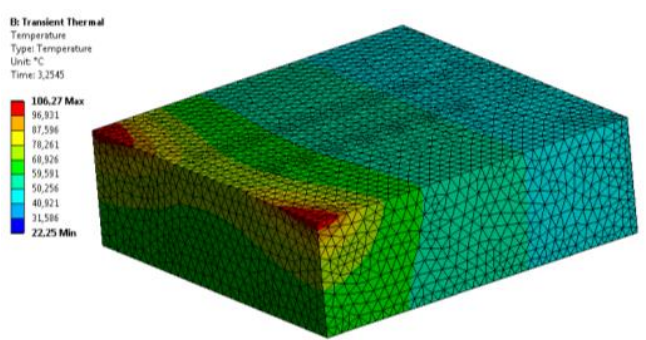

Fig. 8. Temperature changes in time, a) $t=0.3[s]$, b) $t=1.16[s]$, c) $\mathrm{t}=3.25[\mathrm{~s}]$.

Analyzing temperature changes during the simulation of the milling process variable in time (see Fig. 8) one can notice temperature changes in the test volume at the transition of the milling head along the machined surface. An interesting effect is an increase in temperature at the edges of the sample observed in the final phase of milling. The observed phenomenon requires further bench tests.

\section{Summary}

The paper presents a method of numerical determination of temperature in the machining zone during milling of copper alloy. The proposed calculation model can be useful for the determination of temperature distributions in other types of materials.

Analyzing the obtained results, it was found that the results were highly consistent with the results obtained on the test stand. Such studies have been presented in the paper [1]. Recognizing the phenomena of heat transfer is important in terms of optimization of the machining process and obtained dimensional accuracy of the final product. The second aspect of the research is the evaluation of the influence of temperature changes in the machining zone on the durability and reliability of cutting tools.

\section{References}

1. L. Nowakowski, M. Skrzyniarz, E. Miko, J. Takosoglu, S. Blasiak, P. Laski, G. Bracha, D. Pietrala, J. Zwierzchowski, M. Blasiak, Influence of the cutting parameters on the workpiece temperature during face milling, in Experimental Fluid Mechanics 2016 (EFM16), edited by P. Dancova (E D P Sciences, 17 Ave Du Hoggar Parc D Activites Coutaboeuf Bp 112, F-91944 Cedex A, France, 2017)

2. M. Blasiak, S. Blasiak, The application of integral transforms to solving partial differential equations of the fractional order, in ENGINEERING MECHANICS 2017 (ACAD SCI Czech Republic, Inst Thermomechanics, Dolejskova 5, Prague 8, 182 00, Czech Republic, 2017), 150

3. M. Blasiak, S. Blasiak, Application of fractional calculus in harmonic oscilator, in ENGINEERING MECHANICS 2017 (ACAD SCI Czech Republic, Inst Thermomechanics, Dolejskova 5, Prague 8, 182 00, Czech Republic, 2017), 146

4. P. Niesłony, W. Habrat, P. Laskowski, Mechanik 88, $71(2015)$

5. S. Blasiak, Int. J. Heat Mass Transfer 100, 79 (2016)

6. S. Blasiak, J. E. Takosoglu, P. A. Laski, D. S. Pietrala, J. Zwierzchowski, G. Bracha, L. Nowakowski, M. Blasiak, Experimental and simulation flow rate analysis of the $3 / 2$ directional pneumatic valve, in Experimental Fluid Mechanics 2016 (EFM16), edited by P. Dancova (E D P Sciences, 17 Ave Du Hoggar Parc D Activites Coutaboeuf Bp 112, F91944 Cedex A, France, 2017)

7. P. A. Laski, S. Blasiak, J. E. Takosoglu, D. S. Pietrala, G. F. Bracha, J. Zwierzchowski, L. Nowakowski, K. Borkowski, M. Blasiak, Study of the effect of temperature on the positioning accuracy of the pneumatic muscles, in Experimental Fluid Mechanics 2016 (EFM16), edited by P. Dancova (E D P Sciences, 17 Ave Du Hoggar Parc D Activites Coutaboeuf Bp 112, F-91944 Cedex A, France, 2017)

8. J. Liu, C. Ren, X. Qin, H. Li, Int. J. Adv. Manuf. Technol. 72, 693 (2014)

9. R. Chatys, K. Piernik, Composites Theory And Practice 18, 103 (2018) 